\title{
ELEMENTOS PARA DESARROLLAR EL SENTIDO DE PERTENENCIA EMPRESARIAL
}

\author{
Por: Jesús Alvarez Rodríguez*
}

El funcionamiento de los sistemas casi siempre depara comporta mientos comúnmente catalogados como impredecibles, pero que en el fondo responden a causas que se encuentran encubiertas por la brecha de tiempo que se abre entre el momento en que se originan y en el que se manifiestan o aprecian $y$, por supuesto, son más difíciles de identificar en la medida en que los resultados de ese desfase se vislubren retardadamente.

Causa asombro, por no decir que perplejidad, esta afirmación:

"Dos años después de que la publicación de En busca de la excelencia identificara las 43 empresas mejor administradas de Estados Unidos, 14 de ellas se encontraban en dificultades económicas. Según un estudio de la Revista Busines Week, esta situación se debía a una incapacidad de reaccionar y responder adecuadamente a los cambios

Probablemente el sólo hecho de haber sido destacadas esas empresas en el best- sellers, provocó la reacción de la revista; pero son muchas las organizaciones que han corrido $y$ correrán igual suerte. Como punto de referencia, se da por sentada la razón y la pregunta certera sería: ¿Por qué no reaccionaron al cambio?... Porque, todo lo que sobrevino después no fue sino una consecuencia lógica de lo primero.

$\mathrm{Si}$ estas empresas fueron tomadas como modelo es porque, indudablemente, exhibian cualidades que merecían ser admiradas; por lo tanto, se tiene que dar por sentado el hecho que tenían claramente definida la misión, estaban enfocadas, la visión las enrumbaba hacia el aprovechamiento de

\footnotetext{
1 TUCKERT, Robert B. Cómo

administrar el futuro. Barcelona:

Grijalbo, 1992,p.13
} 
oportunidades y la estrategia relacionada se ajustaba a las circunstancias vigentes. En este marco contaban con las fortalezas necesarias y la flexibilidad requerida para hacer frente a los cambios provenientes del entorno.

Los argumentos que enseguida se sustentan están encaminados a demostrar que todas esas cualidades que se enunciaron precedentemente no son ni serán suficientes para mantener a una organización a flote cuando está expuesta a la competitividad; probablemente, fueron suficientes para desenvolverse en medio de un ambiente de competencia. El planteamiento central gravitará, entonces, alrededor de una nueva forma de concebir la relación empresario-trabajador.

Las expectativas se acentúan sobre esta percepción cuando se gira alrededor del siguiente enfoque:

"Durante los intentos por lograr cambios esenciales como la reingeniería de procesos, el liderazgo por sí solo no ha probado ser suficiente para compensar las corrientes ocultas de la cultura corporativa, los intereses personales y las agendas privadas"...

El común denominador de toda esta nueva ola de enfoques consiste en que, para funcionar, se requiere que modifiquemos la forma en que la gente se comporta ${ }^{2}$

La primera premisa se perfila sosteniendo que tanto la misión como la visión y la estrategia están definidas en términos que sólo sirven de inspiración para los empresarios, en el mejor de los casos; pero, no dejarán de presentarse eventos en que no serán más que entusiastas declaraciones redactadas impecablemente por expertos y que sólo se muestran para estar a la moda. Pero en uno y otro caso $\mathrm{y}$, naturalmente más en el segundo, no contienen en sus entrañas elementos realmente poderosos que sirvan para estimular a los trabajadores en términos de interés y concentración de manera similar a como se motiva a los empresarios. En otros términos,

2 Scott morgan, Peler, Las Reglas no escritas del Juego. México: Mc Graw Hill, 1995, p.12 
no se plasman incentivos para tratar de reorientarles el comportamiento.

Desde otro punto de vista es posible que se presuponga que el salario que se reconoce a la fuerza laboral, basta para evocar los mejores valores, para lograr un desempeño adecuado y para trabajar todo el tiempo en función de los intereses de la empresa. Sin embargo, en la práctica esa aspiración no es totalmente cierta.

Esa apreciación la desvanece Frederick Herzberg en la Teoria de los dos Factores. Para reforzar el enfoque en que se apuntala este razonamiento es oportuno reseñar que las teorías de Herzberg y Maslow, son concordantes. Según Herzberg son dos los factores que motivan al nombre. Los primeros los denominó motivadores y son: Trabajo desafiante, logros, desarrollo en el trabajo, responsabilidad, progreso y reconocimiento. Los otros los denominó factores de mantenimiento, de higiene 0 de contexto del trabajo y son: Posición social, relaciones interpersonales, calidad de la supervisión, políticas y administración de la compañía, condiciones de trabajo, seguridad de empleo y sueldo. Herzberg y sus colaboradores, asimismo, comprobaron que éstos sólo eran elementos de descontento y no motivadores. En otras palabras, "sí existen en un ambiente de trabajo en gran cantidad y calidad, no producen insatisfacción; sin embargo, si no existen surgiría la insatisfacción" ${ }^{\prime 3}$

Esta teoría tiene confirmado asidero en la práctica; por eso se admite que el trabajador se preocupará por desempeñarse adecuadamente en el trabajo en función del sueldo, pero éste por sí mismo no despertará sentido de pertenencia que lo induzca a vivir psicológicamente conectado a la empresa. Defenderá, como es natural, los intereses; pero, no llegará a hacerlo con el fervor y con la pasión con que lo haría el empresario.

Algunas organizaciones ofrecen recompensas tentadoras a los vendedores o a los ejecutivos que

3 KoONTZ, Harold y WEIHRICH, Heinz. Administracion: Una Perspectiva Global. 10 De. México: Mc Graw Hill, 1994,ps.469-470. 
están ubicados en los puestos claves; pero, eso no es suficiente.

En primer término, ese tipo de reconocimientos se asociará a la larga con el sueldo; es decir, asumirá para el trabajador el mismo significado del sueldo. Mirado desde otro perfil, en términos de sistemas, tanto contribuyen al logro de los objetivos quienes se desempeñan en las áreas de inventarios por ejemplo, como los que se desenvuelven en los puestos más encopetados o los que están más cerca de los puntos de venta.

Estos argumentos inducen a concluir que, en la contempo raneidad, cuando se impone la competitividad, los recursos humanos juegan un papel determinante en el desempeño de la empresa. Por eso es interesante pensar que resultaría prodigioso reinventar los términos de recompensa por el trabajo realizado, y plasmar en el contrato cláusulas que inciten o comprometan permanentemente al trabajador a estar en función de los intereses de la empresa por su propia iniciativa, sin que el empresario tenga que estar continuamente supervisando las labores desarrolladas. Creer que los niveles de supervisión y los sueldos son factores suficientes para garantizar la dedicación del trabajador a la causa de la empresa es sólo una buena esperanza.

El punto a relievar aquí es que es preciso instaurar mecanismos de recompensa que reflejen los avances de la empresa: que el trabajador logre entender que el progreso 0 los desaciertos afectan de manera visible sus ingresos. Practicando un modelo de esta naturaleza, el trabajador tomará conciencia de que en principio está corriendo riesgos semejantes a los que está expuesto el empresario; por consiguiente, sentirá forzosamente el comportamiento de la empresa y las variables que lo afectan.

La adecuación de la empresa a los cambios está supeditada a dos factores, uno endógeno y otro exógeno. Normalmente los cambios se originan en el factor exógeno y se pueden detectar a través de diversas vertientes pero, la más reveladora, la que lo delata desde el principio y más nítidamente es el comportamiento 
del cliente. De manera que si se logra estimular al trabajador para que desarrolle esa "propensión natural, inconsciente", se habilitará para que lo identifique y siga la evolución. Le corresponderá luego al empresario asimilarlo y apelar a la tecnología apropiada.

El papel principal que les corresponderá desempeñar es el de olfatear los cambios que se están produciendo en el entorno y que son a la larga los que determinarán la supervivencia de la empresa. Los cambios no aparecen de la noche a la mañana. Tienen, como todas las cosas, una evolución natural, un período de gestación. Naturalmente esa evolución se produce ahora en menos tiempo que antes. La idea básica consiste en lograr que el trabajador desarrolle "instintos" que permitan el estímulo 0 el reconocimiento de las manifestaciones del medio que afecten el desempeño de la empresa. En otros términos, incitar en el trabajador "sentidos" similares a los del empresario, que detecten los comportamientos que se relacionen con los intereses de la empresa.

No es lo mismo trabajar para que los resultados se canalicen a otro destino, que cuando de alguna manera desembocan en parte en las propias arcas. En este caso las capacidades de detección de los cambios que se desarrollan no tienen comparación con las que se activan en el otro caso.

Esa capacidad de compromiso, de desprendimiento, esa pasión por defender los intereses no solamente en el momento presente sino a través de períodos de tiempo extendidos, estratégicos, es lo que denomino "sentido de pertenencia empresarial". Al fin y al cabo se trata de la provocación de conductas orientadas en algún sentido y que permanecerán vigentes mientras se libre la batalla con la competencia. $Y$ eso puede ser a corto o largo plazo.

Es fácil deducir del planteamiento, que se trata de una cualidad que no es connatural y que tampoco es susceptible de ser avivada por el sueldo $y$, por consiguiente, es 
concerniente inducirla, despertarla y, además, infundirle fuerzas para que sea capaz de autosostenerse. Es necesario acudir a otro artificio que logre no sólo despertarla sino que la mantenga vigilante a través del tiempo. Para dinamizar y mantener latente una característica de esa naturaleza, los incentivos que la provoquen tienen que tocar fibras muy sensibles que alcancen, por un lado, a enardecer; pero, que a la vez produzca un efecto sostenido.

No se pretende, por supuesto, que la participación del trabajador sea similar a la del empresario. Tendrá que ser, necesariamente, diferente porque los riesgos que se corren no afectan los intereses de uno y otro en la misma proporción. La del empresario tiene que ser indudablemente mayor. Tal vez al final del ejercicio contable sea el momento adecuado para saldar cuentas.

Ese momento será la oportunidad para encender la llama y alimentar la pira con combustible suficiente para que se mantenga ardiendo por períodos prolongados de tiempo a pesar de las turbulencias y los embates del entorno.
*El Autor es Ingeniero Industrial (UIS). Postgrado en Elaboración y Evaluación de Proyectos de Desarrollo Económico. (OEA- CETREDE -U.Atlántico). Master en Administración de Empresas (OEA-INSORA U. de Chile) 